\title{
Morbidity Pattern Study among Pregnant Women Attending Antenatal Clinic at Community Health Centre
}

\author{
Jalpa Suthar, Kripa Patel \\ Department of Pharmacology, Ramanbhai Patel College of Pharmacy, Charotar University of Science and Technology, CHARUSAT- \\ campus, Changa,Tal- Petlad, Dist- Anand Pin code -388421. Gujarat, INDIA.
}

\begin{abstract}
Background: About half a million women die every year of causes related to obstetrics complication. Complication can arise at any time during pregnancy; child birth and post natal period and in absence of intervention, there is a high feto-maternal morbidity and mortality. The aim of the study was to know the morbidity pattern and pregnancy outcome among the antenatal attending to the community health centre. Method: A prospective observational study was conducted on pregnant women during August 2013 to December 2013. Data regarding maternal socio-demographic profile and antenatal profile was collected. Results: A total 512 pregnant women attended the health centre of whom, $88.87 \%$ patients had at least one morbidity pattern or complain. In our study moderate anemia (65.26\%), severe anemia $(13.79 \%)$ and pregnancy induced hypertension $(4.78 \%)$ were the most common morbidities. Further, morbidity pattern like, pregnancy associated common complains, mild anemia abnormal presentation, abortion, preterm labor, oligohydramnios, urinary tract infection and HIV were also reported. Conclusion: Maternal morbidity is notably high, although most of the common problems were not lifethreatening. They are more likely to have marked influence on their well-being and health status in the long run. Most conditions could be addressed through provision of health promotion and preventive interventions.
\end{abstract}

Keywords: Antenatal, Obstetric complication, Outcome of pregnancy, Pregnancy.

\section{INTRODUCTION}

Maternal deaths have been described as the tip of the iceberg and maternal morbidity as the base. For every woman who dies of pregnancy-related causes, 20 or 30 others experience acute or chronic morbidity, often with permanent sequel that undermine their normal functioning. ${ }^{1,2}$ These sequel can affect women's physical, mental or sexual health, their ability to function in certain domains (e.g. cognition, mobility, participation in society), their body image and their social and economic status. ${ }^{3,4}$ Not surprisingly, the burden of maternal morbidity - like that of maternal mortality - is estimated to be highest in low- and middle-income countries, especially among the poorest women. ${ }^{4}$ Pregnancy is a vital stage in every woman's life. It is a period of expectant waiting and one that all women aspire to experience at least once in their lifetime. It is a fervent hope of all mothers-to-be to have a safe and healthy pregnancy. ${ }^{5}$

Pregnancy is a physiological state of stress on the body and by itself makes women prone to many disorders and diseases. This, coupled with the complications of pregnancy can have various severe deleterious effects on the health of the mother and the fetus. ${ }^{6,7}$ WHO report 2005 shows that one woman dies of pregnancy and childbirth related complications every minute, i.e. more than half a million every year. ${ }^{8}$ While most pregnancies and births are uneventful, all pregnancies are at risk. Around 15\% of all pregnant women develop a potentially life-threatening complication that calls for skilled care and some will require a major obstetrical intervention to survive (WHO, 2000). ${ }^{8}$ In India every year about 8 million
DOI: 10.5530/ijopp.10.4.56

Address for correspondence: Dr. Jalpa Suthar Assistant Professor, Department of Pharmacology, Ramanbhai Patel College of Pharmacy (RPCP), Charotar University of Science and Technology (CHARUSAT), At \& Post- Changa, Tal- Petlad, Anand, Gujarat-388 421. INDIA.

E-Mail: jalpasuthar.ph@charusat. ac.in

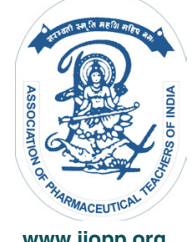


babies are born underweight ${ }^{10}$ and 0.5 million are born with specific morbidities. ${ }^{11}$

Not surprisingly, the burden of maternal morbidity - like that of maternal mortality - is estimated to be highest in low- and middle-income countries, especially among the poorest women. ${ }^{12}$ Complications of pregnancy, childbirth, and the postpartum period may lead to death or cause a continuum of morbidities that affect a woman's health for short or long-term periods during and after pregnancy, and even throughout her life.

The common causes of maternal death include hemorrhage, hypertension, infection, obstructed labor and unsafe abortion. ${ }^{13}$ Also the other particular etiology can be due to early marriage during teens, often pregnancies, motherly malnutrition issue, respiratory obstacle, etc. ${ }^{14}$ Complications can arise any time during pregnancy, child birth and post natal period and in absence of skilled intervention, there is a high fetomaternal morbidity and mortality. ${ }^{15}$ In India, data show that $70 \%$ of mothers, who had four or more antenatal check-ups, delivered in institutions compared with $7 \%$ for those who had no antenatal check-ups. ${ }^{16}$ The true burden of maternal morbidity is still not known. However, existing estimates and calculations are not based on standard, well documented and transparent methods. Such methods are not very useful and have poor validity for informing efforts to address the problem of maternal morbidity. Chief among the reasons for the difficulty in accurately measuring maternal morbidity is the absence of a common definition and of standard identification criteria. This problem is compounded by the inaccuracy of vital records due to inadequate health information systems. ${ }^{17} \mathrm{~A}$ systematic review of obstetric and non-obstetric complications in antenatal is requiring providing better maternal and fetal outcome. Therefore, the study was conducted to study morbidity pattern and pregnancy outcome among the antenatal attending to the community health Centre.

\section{METHOD}

A prospective observational study was conducted on pregnant women attending to the antenatal clinic of Community Health Centre, Sarsa. The study was conducted for a period of 5 months from August-2013 to December-2013. All antenatal attending to the centre were included in the study. Study was initiated after getting approval from human ethics committee [protocol (RPCP/PG/2012-2013/R15) was approved by Rathi Ethics Committee, Ahmedabad]
Data Collection: All antenatal attending to clinic were observed for the morbidity study and all necessary information recorded as mentioned in the Case Record Form (CRF). The participation in the study was on voluntary basis, written informed consent was obtained from study participants, anonymity and confidentiality was assured and emphasized. During data collection patient's personal demographical details, complains, investigations, diagnosis and prescribed treatment were recorded in the CRF by personal interview with antenatal Statistical Analysis: All the calculations were performed by using Microsoft Excel 2007. Data are expressed as percentage.

\section{RESULTS}

A total 512 pregnant women had attended antenatal clinic during the period of study. Out of 512 pregnant women patients, $445(88.87 \%)$ patients had morbidity complain. Majority of patients $(57.4 \%)$ were from the age group 21-25 years. The mean age of patients was found to be $23.58 \pm 3.52$ years.

\section{Parity distribution}

Gravidity is the number of times that a woman has been pregnant and parity is the number of times that she has given birth to a fetus with a gestational age of 24 weeks or more, regardless of whether the child was born alive or was stillborn. In our study, 204 (39.84\%) patients had null parity, 194 (37.89\%) patients were having signal parity or second gravid and 73 patients had 2 parities.

\section{Distribution of patients with maternal morbidity}

Anemia was most common morbidity in pregnant women with the prevalence of $86.91 \%$. Moreover, complains such as Fever, body ache, headache, abdominal pain, backache, vertigo, diarrhea and cold flu like morbidities were considered as in common morbidity. Apart from this, an obstetrics complication such as oligohydramnios, diagnosed in 5 patients. Oligohydramnios is a condition

\section{Table 1: Parity Distribution of Patients.}

\begin{tabular}{ccc} 
PARITY & NO. OF PATIENTS & $\begin{array}{c}\text { PERCENTAGE OF } \\
\text { PATIENTS }\end{array}$ \\
\hline 0 & 204 & $39.84 \%$ \\
1 & 194 & $37.89 \%$ \\
2 & 73 & $14.26 \%$ \\
3 & 26 & $5.08 \%$ \\
4 & 11 & $2.15 \%$ \\
5 & 2 & $0.39 \%$ \\
6 & 2 & $0.39 \%$ \\
\hline
\end{tabular}


described as inadequate amniotic fluid present in placenta which is essential for fetus growth and development. Low fetal weight was observed in oligohydramniotic patients. Pregnancy induced Hypertension was diagnosed in 26 patients, which is a life-threatening morbidity. Vaginal bleeding, morbidity was found in 9 patients during antepartum. Other morbidities like preterm labor was found in 7 patients, 3 patients diagnosed with GDM in their $24^{\text {th }}$ to $28^{\text {th }}$ week of gestation, HIV found in 5 patients during the study. Postpartum morbidity like breast problems was detected in 3 patients.

Based upon the reported symptoms an obstetric and non-obstetric complication was identified and shown in Table: 2. Altogether, 445 (88.87\%) women experienced these problems during pregnancy.

Morbidities were classified according to the type of severity and associated complications as indicated in Figure 4, larger number of patients had morbidities of mild types (71.51\%), 128 patients had severe type of morbidities followed by $4.34 \%$ life threatening morbidities like pregnancy induced hypertension, very severe anemia at third trimester, HIV which leads to maternal and neonatal mortality and other complications.

\section{Prevalence of anemia among antenatal}

'Total 500 patients' data regarding Hemoglobin level were available; therefore, data of the same were included in to this result analysis. Mean $\mathrm{Hb}$ of patient was found to be $7.6 \pm 1.2 \mathrm{gm} / \mathrm{dl}$. Among 500 patients, only 55 patients had hemoglobin in a normal level, followed by highest number of patient (355) had moderate type of Anemia, 75 patients had severe, 11 patients had mild and 4 patients had very severe type of anemia. Anemia was classified according to the WHO defined criteria.

Prevalence of anemia according to trimester; Looking in to prevalence of anemia, highest numbers of anemic patients were seen in third trimester, out of which maximum number of patients had moderate anemia.

Regarding the mode of delivery, 145 patients' data were available during study period. Among 145 patients, 97 patients had normal delivery, 25 patients had normal delivery with episiotomy, 19 patients were delivered by caesarean section, and 2 pregnant women delivered still baby and intrauterine fetal death reported in 2 women.

\section{DISCUSSION}

The present study is the first, to our knowledge, to involve the use of population-based data to summarize the prevalence of maternal morbidity during labor and delivery hospitalizations in the community health Centre. There are many studies on the prevalence and determinants of maternal mortality but very less work has been done on maternal morbidity. The main reason for this lacuna of such types of information is because of the lack of adequate and precise information on obstetric morbidity and the under reporting of underlying obstetric diagnosis.

\begin{tabular}{|c|c|c|c|}
\hline Sr. No & Type of Morbidity & No. & Percentage \\
\hline \multicolumn{4}{|c|}{ Obstetric } \\
\hline 1 & Pregnancy Induced Hypertension & 26 & $4.78 \%$ \\
\hline 2 & Abnormal Presentation & 9 & $1.65 \%$ \\
\hline 3 & Abortion & 9 & $1.65 \%$ \\
\hline 4 & Preterm labor & 7 & $1.29 \%$ \\
\hline 5 & Oligohydramnios & 5 & $0.92 \%$ \\
\hline 6 & Prolonged labor pain & 5 & $0.92 \%$ \\
\hline \multicolumn{4}{|c|}{ Non-obstetric } \\
\hline 7 & Moderate Anemia & 355 & $65.26 \%$ \\
\hline 8 & Severe Anemia & 75 & $13.79 \%$ \\
\hline 9 & Common & 24 & $4.41 \%$ \\
\hline 10 & Mild Anemia & 11 & $2.02 \%$ \\
\hline 11 & Human Immunodeficiency Virus & 5 & $0.92 \%$ \\
\hline 12 & Very severe Anemia & 4 & $0.74 \%$ \\
\hline 13 & Gestational Diabetes Mellitus & 3 & $0.55 \%$ \\
\hline 14 & Breast Problems & 3 & $0.55 \%$ \\
\hline 15 & Urinary infection & 2 & $0.37 \%$ \\
\hline 16 & Thyroid & 1 & $0.18 \%$ \\
\hline
\end{tabular}


In our study, out of 512 pregnant women, 455 (88.87\%) women experienced one or more episodes of the health problems during the study this finding being similar to those of other studies. Life threatening, and serious morbidities were found to be $4.34 \%$ and $24.15 \%$ respectively, which was found less than other studies. G Rama padma stated study showed a high prevalence of maternal morbidity in rural areas of Andhra Pradesh. Especially in the less developed district, nearly 95 percent of the women experienced at least one of the

\begin{tabular}{ccc}
\hline \multicolumn{3}{c}{ Table 3: Prevalence of Anemia among Antenatal. } \\
\hline TYPES OF ANEMIA & NUMBER & PERCENTAGE \\
\hline NORMAL & 55 & $11.00 \%$ \\
MILD & 11 & $2.20 \%$ \\
MODERATE & 355 & $71.00 \%$ \\
SEVERE & 75 & $15.00 \%$ \\
VERY SEVERE & 4 & $0.80 \%$ \\
TOTAL & 500 & $100.00 \%$ \\
\hline
\end{tabular}

\begin{tabular}{ccccc}
\hline \multicolumn{5}{c}{ Table 4: Prevalence of Anemia According to Trimester. } \\
\hline TRIMESTER & MILD & MODERATE & SEVERE & VERY SEVERE \\
\hline 1ST & 0 & 5 & 1 & 1 \\
2ND & 6 & 172 & 34 & 0 \\
3RD & 5 & 178 & 40 & 3 \\
\hline
\end{tabular}

\begin{tabular}{ccc}
$\begin{array}{c}\text { Table 5: Mode of delivery and its outcome. } \\
\text { MODE OF DELIVERY }\end{array}$ & & \\
\hline NUMBER & PERCENTAGE \\
\hline Normal & 97 & $66.90 \%$ \\
Normal with episiotomy & 25 & $17.24 \%$ \\
Lower segment caesarean section (LSCS) & 19 & $13.10 \%$ \\
Still Birth & 2 & $1.38 \%$ \\
Intrauterine fetal death & 2 & $1.38 \%$ \\
Total no. of patients & 145 & $100.00 \%$ \\
\hline
\end{tabular}

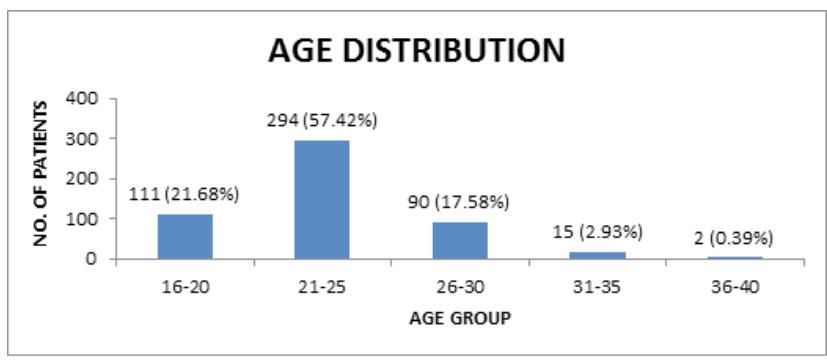

Figure 1: Age Group Distribution of Patients

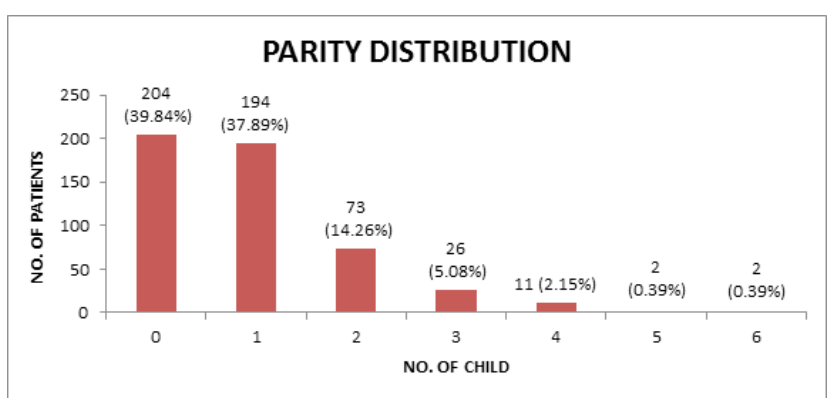

Figure 2: Parity Distribution of Patients

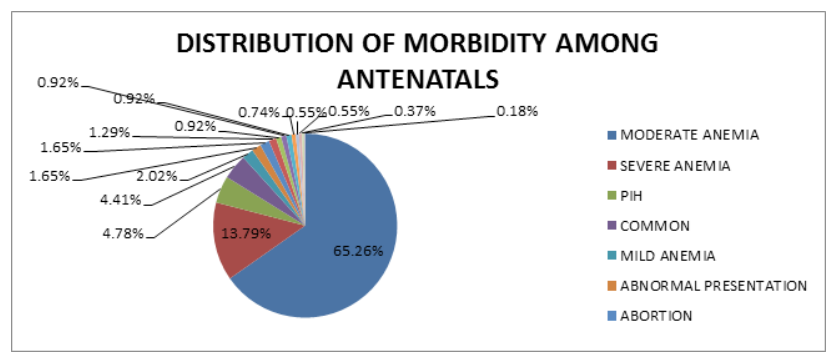

Figure 3: Distribution of maternal morbidity amongst antenatal

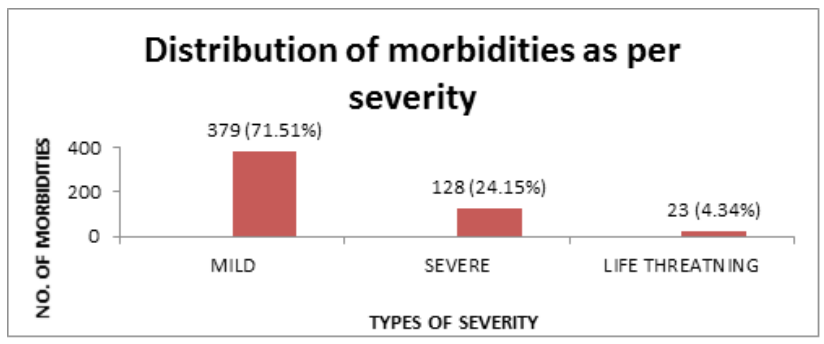

Figure 4: Classification of morbidities as per severity 


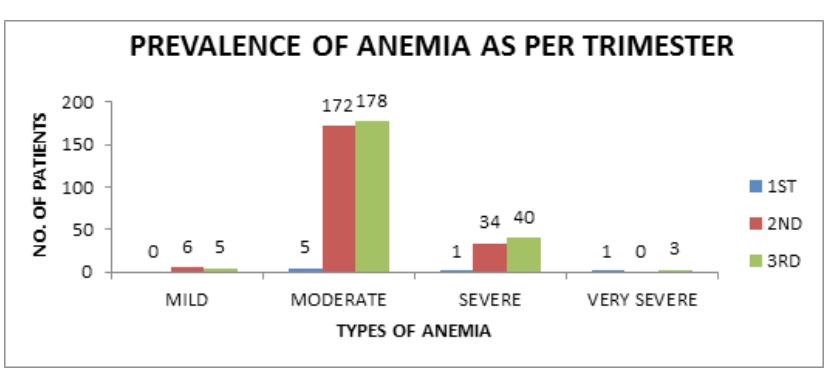

Figure 5: Prevalence of Anemia According to Trimester

morbidities and in the developed district it is 61 percent. Life threatening, and serious morbidities are experienced by 39 and 54 percent in the less developed; 15 and 46 percent of women in developed district respectively. ${ }^{3}$ The mean age of the patients was $23.6 \pm 3.5$ years. pragti chhabra et al., study found the mean age of the patient was $26.3 \pm 5$ years. ${ }^{18} \mathrm{~A}$ study by Manik S. Shirpukar et al., also showed its results that about $83.5 \%$ pregnant women belonged to age group of 20-29 years and their average age is too 25.7 years. $^{19}$

The present study reported a higher prevalence anemia $(86.91 \%)$, pregnancy induced hypertension $(7.9 \%)$ and a lower prevalence of urinary tract infections $(0.37 \%)$, gestational diabetes $(0.55 \%)$. Whereas, T. Ruwanpathirana et al study reported a higher prevalence pregnancy induced hypertension $(9.6 \%)$, gestational diabetes $(4.6 \%)$ and a lower prevalence of urinary tract infections $(2.5 \%){ }^{20}$

Anemia in Pregnancy (AIP), according to WHO is defined as hemoglobin concentration below $11 \mathrm{gm} / \mathrm{dl}$. WHO has estimated that the prevalence of anemia is $14 \%$ in developed and $51 \%$ in developing countries, where as in India it is $65-75 \% .{ }^{21}$ Majority of instances of associated Morbidity and Mortality during pregnancies are found in patients of developing countries. ${ }^{22}$ Our study revealed a high prevalence of anemia (86.91\%) among pregnant women in rural area. Almost all patients were uneducated and unaware of diet which must be taken during pregnancy to fulfill the nutritional support for the mother and development of fetus. This could be the reason for high prevalence of anemia in rural population. Majority of the study population has a moderate degree of anemia $71 \%$ followed by mild degree $2.20 \%$, severe degree $15 \%$, and $0.80 \%$ very severe degree of anemia with $11 \%$ of pregnant women have the normal range of hemoglobin. One study too showed the results with maximum of Moderate anemia cases as about 31\%, followed by Mild anemia about $26.1 \%$ and severe anemia was only $2 \% .{ }^{19}$ Our study represents somewhat similar rate of prevalence of anemia when compared with the other studies conducted by Nadeem Ahmad in rural population of Maharashtra (74.84\%), studies carried out in the rural areas of Delhi by Virender $(96.5 \%)^{20,21}$ and in rural community in Andhra Pradesh. ${ }^{21}$ Similarly a study too revealed that about $63.42 \%$ women were anemic. ${ }^{22}$

Hypertension was detected in 26(4.78\%) women. This complicates $7-10 \%$ of Pregnancies. ${ }^{23}$ The disease is a symptomatic initially and if detected early one can prevent eclampsia, IUGR and other complications. Eclampsia is responsible for $12 \%$ of maternal deaths. ${ }^{24}$

In present Study, out of 512 women a total 145 women had delivered baby during study period. Among 145 patients, 97(66.90\%) patients had normal delivery, $25(17.24 \%)$ patients had normal delivery with episiotomy, $19(13.10 \%)$ patients were delivered by caesarean section, and $2(1.38 \%)$ pregnant women delivered still baby and intrauterine fetal death reported in $2(1.38 \%)$ women. Two such studies show identical results as patients with normal deliveries were $43.5 \%$ and $41.38 \%$, about $54.5 \%$ and $48.27 \%$ patients were delivered with Caesarean section respectively. $(25,26) 12$ such cases were also observed where fetus death too was notified. ${ }^{22}$

\section{CONCLUSION}

Maternal morbidity is notably high, while most of them were not life-threatening. They are more likely to have marked influence on their well-being and long-term health status. Most conditions could be addressed through provision of health promotion and preventive interventions. Health education at community level is necessary to create awareness about importance of ante natal care, institutional delivery and post natal care in addition with increasing rate of literacy and women empowerment.

\section{ACKNOWLEDGMENT}

We would like to thank Dr. Vincent J Christian, Superintendent, Community Health Centre Sarsafor providing guidance and support during data collection.

\section{CONFLICT OF INTEREST}

The authors declare that there is no conflict of interests regarding the publication of this paper.

\section{SUMMARY}

A prospective observational study was carried out at community health centre, Sarsa (rural area) between 
august 2013 to december 2013.All pregnant women who attended antenatal clinic during the course of study period was included in to the study. The mean age of the patients was found to be $23.6 \pm 3.5$ years. A total 16 types of maternal morbidities were found during the study period, among 16 , prevalence of anemia was found to be higher $(89 \%)$. Followed by pregnancy induced hypertension (4.78\%), abnormal presentation $(1.65 \%)$, antepartum hemorrhage $(1.65 \%)$, oligohydramnios $(0.92 \%)$, preterm labor $(1.29 \%)$, GDM $(0.55 \%)$, HIV $(0.92 \%)$, and thyroid $(0.18 \%)$. Regarding the mode of delivery, only 145 patients' data were available. Among 145 patients, 97 patient had normal delivery, 25 patient had normal delivery with episiotomy, 19 patients were delivered by caesarean section, 2 pregnant women delivered still baby, and intrauterine fetal.

\section{REFERENCES}

1. Ashford L. Hidden suffering: disabilities from pregnancy and childbirth in less developed countries. Population Reference Bureau; 2002. Available from: http://www.prb.org/pdf/hiddensufferingeng.pdf [accessed 24 June 2013].

2. Reichenheim ME, Zylbersztajn F, Moraes CL, Lobato G. Severe acute obstetric morbidity (near-miss): a review of the relative use of its diagnostic indicators. Arch Gynecol Obstet. 2009;280:337-43. http://dx.doi.org/10.1007/s00404-0080891-1 pmid: 19112576.

3. Pacagnella RC, Cecatti JG, Camargo RP, Silveira C, Zanardi DT, Souza JP, et al. Rationale for a long-term evaluation of the consequences of potentially life-threatening maternal conditions and maternal "near-miss" incidents using a multidimensional approach. J Obstet Gynaecol Can. 2010;32:730-8. pmid:21050503.

4. Storeng KT, Murray SF, Akoum MS, Ouattara F, Filippi V. Beyond body counts: a qualitative study of lives and loss in Burkina Faso after 'near-miss' obstetric complications. Soc Sci Med. 2010;71(10):1749-56. http://dx.doi.org/10.1016/j. socscimed.2010.03.056 pmid: 20541307)

5. Ashwini S, Shivaswany MS, Katti S, Mallapur MD. Profile of Antenatal Women Attending Urban Health Centre, Khasbag, Belgaum. Medica Innovatica. 2012;1(2):43-8.

6. Thaker R, Deliwala K, Jadav MM. Retrospective Comparative Study of Obstetric complications and Maternal Mortality in Registered and Unregistered women at Tertiary Care Hospital. NHL Journal of Medical Sciences. 2013;2(1):28-35.
7. Gogoi M, Unisa S, Prusty R. Utilization of maternal health care services and reproductive health complications in Assam, India. Journal of Public Health. 2014;22(4):351-9

8. The World Health Report 2005 - make every mother and child count. World Health Organization; 2005.

9. Datta KK, Sharma RS, Razack P, Ghosh TK, Arora RR. Morbidity pattern amongst rural pregnant women in Alwar, Rajasthan- a cohort study. Health and Population: Perspectives and Issues. 1980;3(4):282-92.

10. Singh M, Tripathy K, Arya LS. Birthweight gestational age correlates of neonatal mortality Indian. J pediatrics. 1982;49(4);511-7.

11. Paul V.K,SinghM, Sundram K.R, Deorari A.KCorrelates of mortalityamong hospital born neonates with birth asphyxia. Natt Med J landian. 1997;10:54-7.

12. Storeng KT, Murray SF, Akoum MS, Ouattara F, Filippi V. Beyond body counts: a qualitative study of lives and loss in Burkina Faso after 'near-miss' obstetric complications. Social Science and Medicine (1982). 2010;71(10):1749-56.

13. Matthews M. Reviewing Maternal Deaths and Complications to Make Pregnancy and Childbirth Safe. Regional Health Forum. 2005;9(1).

14. Klein J. perinatal morbidity and mortility associated with cesarean section 11 fetal salvage in the presence of stress factor obstet. Gynec.1959;20;1023

15. Thaker R, Deliwala K, Jadav MM. Retrospective Comparative Study of Obstetric complications and Maternal Mortality in Registered and Unregistered women at Tertiary Care Hospital. NHL Journal of Medical Sciences. 2013;2(1):28-35.

16. Sugathan KS, Mishra VK, Retherford RD.Promoting institutional deliveries in rural India: the role of antenatal-care services. National family health survey subject reports; 2001

17. 17. http://www.who.int/bulletin/volumes/91/10/13-117564/en

18. Chhabra P, Guleria K, Saini NK, Anjur KT, Vaid NB. Pattern of severe maternal morbidity in a tertiary hospital of Delhi, India: a pilot study. Tropical Doctor. 2008;38(4):201-4

19. Manik SS, Mamta KS, Prajkta GJ. Pattern of obstetrics complication among pregnant females admitted in a tertiary care centre in central India. International Journal of Reproduction, Contraception, Obstetrics and Gynecology. 2015.

20. Ruwanpathirana T, Fernando DN, Senanayake H. Antenatal morbidity experiences and pregnancy outcome in a cohort of women-a community based study. Journal of the College of Community Physicians of Sri Lanka. 2014;19(1):18-26. DOI: http://doi.org/10.4038/jccpsl.v19i1.7622

21. Vemulapalli B, Rao KK. Prevalence of Anaemia among Pregnant Women of Rural Community in Vizianagaram, North Coastal Andhra Pradesh, India. Asian Journal of Medical Sciences. 2013;5(2):21-5.

22. Frequency, Indications and Maternal Outcome in Obstetric Hysterectomy in a Tertiary Care Centre in India. Dilpreet Kaur Pandher, Alka Sehgal, Nupur Aggarwal. 2015;17(1)

23. Goodburn E, Combell O.Reducing maternal mortality in the developing world: Sector wide approaches may be the key. BMJ. 2001;322:917-30.

24. Hypertension in pregnancy: In High Risk Pregnancy .Hallak M. James DK,Steer PJ,Weiner CP and Gonik B (ed).2 ${ }^{\text {nd }}$ edition. Wb Saunders London.1999:693. 